\title{
Um Rio Dentre os Inumeráveis
}

\section{Wilton Fred Cardoso de Oliveira}

\author{
Mestre em Literatura Brasileira pela UFSC
}

Ler Os Rios Inumeráveis, de Álvaro Cardoso Gomes, é como entrar na Biblioteca de Babel, de Borges, ou perder-se na Biblioteca da Abadia da obra O Nome da Rosa, de Umberto Eco. Como essas bibliotecas, o romance de Gomes não é para um leitor comum, pressupõe um leitor ideal (se pensarmos aqui na Estética da Recepção), face ao diálogo que seu texto mantém com tantos outros de nossa Literatura e da Literatura mundial. Além disso, o romance de Gomes pode ser visto como uma epopéia, se o encararmos como a história da formação do povo brasileiro; centrada no herói, o mutante Fernão Matias Ribeiro. Outro valor presente no romance é a possibilidade de o lermos como uma rapsódia, um segundo Macunaíma, face aos diversos gêneros presentes: cartas, canções populares, conto e outros. Há ainda semelhanças entre os romances de Gomes e de Mário de Andrade, não só na forma, mas na ausência de caráter e na transmutação dos personagens Macunaíma e Fernão. Ambos têm o seu trajeto vertical no território brasileiro. O primeiro nasce na Amazônia e dirige-se a São Paulo em busca de sua identidade: a muiraquitã; o segundo foi aportado na Paraíba, mas o percurso da construção de seu caráter é idêntico ao do personagem de Andrade. Claro que não desconhecemos dessemelhanças, tais como o aspecto histórico, essencial em Gomes, o que não é tão relevante em Mário de Andrade.

Traçamos esse rápido paralelo entre os dois heróis, inicialmente, por considerarmos relevante em virtude do anonimato em que se encontra o romance Os Rios Inumeráveis. É uma obra de grande peso, que até o momento não teve o reconhecimento devido. Não queremos tecer comparações persuasivas, tão somente valorizar o que é digno de ser valorizado.

Comecemos pelo princípio. No princípio era Fernão e Gedeão, ambos paridos pelos deuses, habitavam uma terra selvagem e sem forma. E o corpo de Fernão adentrava as matas. E disse os deuses antes de partirem: "Que haja forma!". E assim se fez. O espírito de Fernão conhecendo a terra, vendo que tudo era bom, chamou-a de Terra de Vera Cruz. À terra conheceu e fecundando-a fez-se índio, boto, escravo, Senhor, traidor, plebeu e Lord. Sentindose solitário entre as estranhas formas, vendo que habitava a terra vazia de deuses, fez para si uma mulher da qual disse: "Esta, afinal, é osso dos meus ossos e carne da minha carne; chamar-se-á varoa, pois de um varão foi formada." (Gênesis, 2:23), e a ela chamou de Fernanda, carne de sua carne. E vendo que tudo era bom, quis ser tão nobre quanto os deuses habitantes do continente que aqui o deixaram. Mas decaído do Olimpo, por haver lutado contra os deuses, a cosmogonia que repetia não passava de simulacro de suas visões celestiais, máscaras de alguém que no sensível tentava resgatar imagens do paraíso.

Como máscara se constituiu a sua existência e a projeção de seus sonhos; não como continuidade, regularidade, tão sonhada por Lord Creek. Este é formas e formas, mutante, assassino, covarde, mentiroso. Herói ou anti-herói de mil faces - legião, como o demônio. Difícil agarrá-lo, vê-lo em sua essência. É esse elemento escorregadio, que se escafedeu, ou não, janela afora, que tentaremos apreender nesse ensaio. 
No capítulo intitulado Noite na Taverna, Fernão assumiu a personalidade Lord Creek destoando de toda a sua tradição, no cosmo até então gerado. Buscou uma linearidade para a sua vida, um fio de Ariadne. Talvez, por isso, esse capítulo seja também linear, fuja da estrutura dos outros capítulos. Não era aqui o Fernão/Fernando mutante, era um elemento que tomou para si uma história que não a dele, uma cultura alheia, idealizada; não foi o resultado de uma realidade fabricada pela sua transmutação. Lord Creek é o retrato do romantismo brasileiro - período do irreal, do idealizada. Eis por que o texto parece fugir à estrutura das outras narrativas que compõem o romance. Da mesma forma que Fernando foge à sua tradição, ao seu nome, nesse capítulo o personagem não se transmuda; reveste-se, imita, finge - como fingem, como imitam os românticos. Como a nossa Literatura desse período não foi original, apesar de assim pretenderse, falso também era o nosso Lord; tampouco poderia ser autêntico - fora desde sua chegada à Terra de Vera Cruz, na figura de Fernão, esse indivíduo sem caráter, que se travestia e se apropriava indebitamente de honras que não Ihe pertenciam. A marca da maldição, de Caim, já Ihe pesava desde suas origens.

Não estamos diante de um personagem tipicamente brasileiro, mas de alguém que já traz as marcas de outra civilização; por isso que ao nos debruçarmos sobre este capítulo, difícil é ficarmos somente no âmbito da Literatura nacional, face a essa ponte de Fernão com a Europa; em segundo lugar, porque o Romantismo foi um momento de falso nacionalismo. Aparentemente podem ter sido tratados temas nacionais, tais como o do índio, do negro, mas a forma e a ideologia eram européias. O Romantismo se pretendeu nacional, porém terminou por repetir formas, deformadas, da literatura dos colonizadores. Diante desse quadro, não poderia Gomes ter recolhido materiais mais representativos, para a construção do capítulo Noite na Taverna, que À Rebours (Às Avessas), do excêntrico Huysmans; As Minas do Rei Salomão, de Ridder Haggard; A Queda da Casa de Usher, de Roger Corman, e conseqüentemente Edgard Allan Poe; por fim, Noite na Taverna, contos inspirados em Lord Byron, cujos narradores, salientando, possuem nomes estrangeiros: Solfieri, Bertran, Gennaro, Claudius Hermann e Johann, bem como o locais de ocorrência das histórias.

Quanto à obra Às Avessas, de Huysmans, centra atenção no excêntrico jovem Jean, pertencente à nobre família dos Floressas des Esseintes. Essa família se compusera de atléticos soldados da velha guarda, de rudes veteranos, mas com o passar dos tempos foi entrando em decadência. Nas palavras do autor

"A decadência dessa antiga casa havia seguido regularmente o seu curso, sem dúvida alguma; o efeminamento dos varões se fora acentuando; como para rematar a obra do tempo, os des Esseintes, durante dois séculos, casaram seus filhos entre si, exaurindo-Ihes o resto de vigor em uniões consangüíneas" (Huysmans, p. 32),

dessa deterioração restou apenas o duque Jean des Esseintes, um jovem franzino de trinta anos, anêmico e nervoso, de faces cavas, olhos azuis de aço frio, nariz erguido conquanto reto, mãos magras e longas. Jean estudou em colégios de Jesuítas, porém essa convivência e aprendizagem não o tornaram religioso, antes sim cético. Posteriormente, ocorrendo a morte dos pais, consome a herança, vende o castelo de Lourps e retira-se para o interior da França onde adquire uma casa e a decora de forma excêntrica.

Nesse romance, Poe está presente através de várias passagens, tais como "Eram, elevadas à sua última expressão, as quintessências de Baudelaire e de Poe;..." (Huysmans, p. 232), ou 
através de semelhanças entre o comportamento de Roderick, personagem de Poe, e de Jean. Comparação tácita como "...havia dias em que tais leituras o quebrantavam, dias em que, de mãos trêmulas e ouvido atento, sentindo-se como desolador Usher, ele era tomado de um transe desarrazoado, de um surdo pavor."(Huysmans, p. 224), ou imagem da narrativa do conto $A$ Queda da Casa de Usher "...era, ao luar, uma fenda entreaberta para um campo mais restrito e mais íntimo;..." (Huysmans, p. 218), além da semelhança entre a descrição física de Roderick e d e s Esseintes. ".. lábios um tanto finos e muito pálidos, mas de uma curvatura extraordinariamente bela; nariz de delicado modelo hebraico, mas com uma amplidão denarinas incomum". (p. 247)

Tal proximidade de traços físicos, de caráter e de comportamento podem ser vistos não só entre entre Roderick e des Esseintes, mas também em Lord Creek. Em primeiro lugar todos são excêntricos; todos estão envolvidos em incestos, em decadência econômica e moral. Todos estão marcados pela imagem da fenda. Será uma constante em Poe, em Gomes, em Huysmans. Será ela quem denunciará a decadência da família (respeitando as variantes de cada narrativa). Em Noite na Taverna lemos "Mais de perto, notei que uma rachadura em ziguezague corria a face do sobrado, desde o teto até as fundações que se perdiam no lodo, às margens do lago." (Gomes, para 206), mesma visão será marcante no narrador do texto de Poe: "Talvez o olhar dum observador minucioso descobrisse uma fenda mal perceptível que estendendo-se do teto da fachada, ia descendo em ziguezague pela parede, até perder-se nas soturnas águas do lago."(Poe, p. 246). Já no filme dirigido por Roger Corman, a fenda é visível, inquietadora para Philip Winter

Outro traço de semelhança entre Jean des Esseintes e Roderick era o caráter efeminado surgindo como elemento de deterioração de uma raça. O des Esseintes final não se assemelha em caráter aos antepassados; por sua vez, Lord Creek não possui uma galeria de antepassados. A única coisa que ele possuía era sua palavra, sua história imaginada, fruto de uma mente doentia, romântica, haja vista que seu passado jazia embalsamado, na figura de Teluka. Sobre si, o Lord poderia narrar, de forma ficcional ou real qualquer história. Se o conceito de razão fosse confrontado com o objeto, este, certamente, denunciaria o seu falseamento, que Lord Creek era máscara, fingimento. Por isso, o objeto nunca era dado ao conhecimento sensível, apenas a ele se referiam - no caso Eleonora, ou Teluka. Era discurso; nunca dado constatável pelos sentidos. O mundo em que estavam imersos era o de sombras, típico do período literário de Abreu, mundo o qual ele encontra ao chegar à Casa de Creek:

"Apeamos sobre a terra enlameada e, à luz da lua, que saíra detrás de uma nuvem, deparamos a Casa de Creek. Que sensação estranha experimentei ante aquela mole erguida soturnamente às margens duma lagoa. A neblina adensara-se, de modo que mal podíamos vislumbrar os contornos do solar, uma construção de dois andares, cujas pedras haviam sido roídas pelo tempo. As janelas assemelhavam-se a órbitas vazias e, numa ou noutra,, tremulava a luz por entre as cortinas." (Gomes, p. 206)

Quanto a Jean des Esseintes, vale lembrar que dele não se afirma que é homossexual, mas que tem formas efeminadas. Está evidente no romance suas relações sexuais marcadas por mulheres viragos. Em se tratando de Fernão, no final da história não restam dúvidas quanto ao desvio sexual ocorrido: Teluka era homem. 
Se analisarmos a questão da Verdade no discurso de Fernão em relação ao conceito de Verdade dos gregos, veremos que para estes

"o discurso pelo qual se tinha respeito e terror, aquele ao qual era preciso submeter-se, porque ele reinava, era o discurso pronunciado por quem de direito e conforme o ritual requerido; era o discurso que profetizando o futuro, não somente anunciava o que ia se passar, mas contribuía para a sua realização, suscitava a adesão dos homens e se tramava assim com o destino." (Foucault, p. 15),

enquanto que o discurso de Fernão não era proferido por quem de direito, bem como o ritual era uma farsa. Suscitou a adesão dos outros, mas como não possuía lastro histórico, ficou desprovido de poder. No embate posterior entre a realidade (na figura do cocheiro), e discurso, venceu a realidade, visto estar lastreada no passado, na observação real do objeto, na constatação histórica de Menezes. O objeto existente, Teluka, existia, mas dito de acordo com o desejo particular do falante - simulacro -, característica do homem romântico.

Voltemos às estruturas. Em se tratando da questão do incesto, tanto os Roderick's quanto em Fernão estão encarcerados no incesto familiar. O amor que aqueles sentiam por sua irmã Madeline era verdadeiro, bem como a existência de sua história e do objeto. Discurso e realidade não se opunham. Já Leonora, irmã de Fernão, era irreal. Tratava-se de um falso incesto, marcando uma falsa aristocracia. Discurso e realidade se contrapunham. Na versão de Gomes, não era o Lord e a suposta irmã que degeneravam, visto que ela nunca existiu, tampouco era mulher. O Lord Creek assim como Oscar Wilde eram degenerados, para o padrão moral de suas épocas. O primeiro pelas relações que mantinha com o jovem Teluka; o segundo pelo processo sofrido, por supostas relações com o jovem Lord Alfred.

Além dessas, outras semelhanças perseguem os personagens das três obras. Todos eram vítimas de uma moléstia congênita a qual viera dizimando as famílias de geração a geração; isso somente constatável em Jean e Roderick. Outra semelhança era a sensibilidade à luz, ao odor das flores e ao barulho que os incomodavam; terceiro, a moradia afastada e solitária. Já entre o personagem de Huysmans e de Gomes é importante salientar que ambos viviam num mundo da palavra, da imitação. A realidade Ihes era insuportável. O mundo imitado, desejado, era o de Roderick. O personagem de Poe pode ser visto aqui como o original e os outros dois personagens como suplementos. Observemos, também, que o cosmo de Fernão é o da ficcionalidade. Toda história da vida de Lord Creek estava diante dos ouvintes Abreu e Varela, mas estes ou desconheciam o livro de Poe, ou o mais provável, haja vista que o Lord se transformara numa espécie de sereia, de elemento sedutor, não viram a verdadeira história de Fernão porque, enquanto românticos, o real não Ihes interessava, antes sim o mundo imaginário. Faltava-Ihes aquela lupa machadiana, que segundo Machado de Assis o tempo negara ao personagem Vilela, manifesto em $A$ Cartomante, que somente o tempo é capaz de conferir aos espíritos ingênuos. Seduzidos pela aura do sonho, seus olhos não podiam ser afetados pelo sensível, estavam cegos para o Phaós, para o Phainómenos. Não haviam sofrido afecções dos objetos, estes que se adequavam às aspirações dos jovens românticos, impossibilitando-os de verem sobre a mesa do Lord a obra de Poe; tampouco associaram a história daquele à do Lord. Retornamos a Poe: $A$ Carta Roubada. Os jovem não viam o que viam, mas o que ansiavam por ver, posto que o olhar deles não era mais ponte entre as coisas, mas nas palavras de Rouanet olhar se comportava como um "...poder sobre as coisas e atividade original, constituinte. Reconhecemos esse olhar soberano. É o do pensamento 
operatório, para o qual a realidade é construída pelo instrumento, que não capta o objeto, mas a estrutura. O mundo é aquilo que nossos instrumentos permitem medir..." (Rouanet, p. 127), nesse caso a idéia do objeto é construída pelo olhar dominador. O olhar opera constituindo o objeto soberanamente, independente da realidade. Nesse caso, capta-se a estrutura e insere-se nele os predicados. Como resultante desse olhar, não era o discurso do Lord que tinha sentido; eram os jovens que estavam envolvidos em um clima que os predispunham a dar um determinado sentido ao discurso do emissor, e configurar uma estrutura apresentada a partir de um olhar soberano, que não se deixou dominar pelo objeto. Isso é possível ser constatado em várias passagens da narrativa.

No início do capítulo Noite na taverna, em que estão insertos Varela e Abreu, surge um cenário propício ao macabro, ao faustiano, aos devaneios da razão, idêntico ao descrito em Noite da Taverna de Álvares de Azevedo. Era o momento adequado para que Satã lhes soprasse aos ouvidos: "vais ler uma página da vida, cheia de sangue e vinho..." (Gomes, p. 201). E foi exatamente nesse clima que entrou Lord Creek, e deparou-se com rapazes embriagados, sofredores de males de amores à espera de aventuras. Haveria melhor lugar para o demônio fazer uma visita? Repete-se o Fausto: Voilà Goethe!

Mas, se não vemos o demônio andando pelas ruas, é porquanto ele sabe que ao manifestar-se, manifesta Deus. Os fenômenos somente são reconhecidos pelos seus opostos. Que estaria fazendo um Lord numa Taverna? A desconfiança deveria ter sido despertada nos jovens. E o que falar do comportamento do cocheiro, da ausência de rigor britânico (apesar de terem notado tal contraste), dos palavrões, da incapacidade deles virem à casa do Lord tal qual se manifestava, e a recusa de escutar a história do cocheiro?! Eles queriam ver tudo, menos o cocheiro. Este era apenas uma peça de uma engrenagem, de um cenário esperado, previsível. Como citamos anteriormente, eles haviam assimilado a estrutura, não o objeto em sua particularidade. Não era o servo que eles queriam escutar, ver; antes sim, o senhor. Estavam seduzidos pelo sonho da aristocracia, assim como Fernão também estava, a ponto de este fabricar para si um passado e vivê-lo. Talvez repouse aí a linearidade desse capítulo, o que não ocorre nos outros. Não há nessa narrativa o embate de raças, de valores que se entrecruzam e que se chocam. A estrutura é de cópia de sociedades mais definidas, possuidoras de um passado. Não havendo, portanto, um Fernão que se transmuda, mas que assimila. Como o Brasil, Fernão era algo transverso: mirava a cultura européia, mas sua estrutura era Norte Americana. Tem Lord Creek um comportamento de um aristocrata inglês, mas sobre sua mesa repousa "um volume luxuosamente encadernado das obras de Edgar Allan Poe" (Gomes, p. 208), autor estadunidense, nascido na cidade de Massachussets em 19 de janeiro de 1809. Eram valores europeus já modificados por valores americanos. Nunca Fernão é o referente direto; sempre transverso. Pensando o texto enquanto participante de um elemento de transição entre Romantismo e Realismo: Da Monarquia à República, que nas palavras de Viotti da Costa "os membros da elite brasileira[em torno desse período] assemelhavam-se, em alguns aspectos, aos fazendeiros sulistas do Velho Sul norte-americano..."(Viotto da Costa, 159). somando-se a esse fato ainda afirma que os republicanos defendiam que um regime monárquico na América era uma anomalia, que deveríamoster como molde o regime republicano. Por conseguinte, tivemos uma República dos Estados Unidos do Brasil. Um Lord europeu norte-americano!...

Quanto a nos depararmos com esse transverso, com esse ser um e outro ao mesmo tempo, com essa capacidade de imiscuir-se por entre as coisas, já nos é de antemão avisado ao iniciarmos a leitura do capítulo V. Deparamo-nos com a frase: "vais ler uma página de vida, cheia de 
sangue e vinho..." (Gomes, p. 201), na seqüência lemos: "as janelas batendo sob o vento, e a cantoria dos sapos enchiam os ares como os de um concerto regido por Satã."( Gomes, p. 209). O demônio não fora desejado por Fausto?! - aparecera-Ihe. Fora almejado pelos jovens manifestara-se! E se os jovens fossem possuidores da lupa machadiana (não seriam jovens) saberiam de antemão que o demônio nada cria. Joga um xadrez sempre esperando que Deus Ihe dê o contralance, caso contrário ele morrerá de solidão, ou cairá no esquecimento humano. Ele toma sempre a feição de, nunca é, criando um mundo da irrealidade, da mentira. Assim é Fernão. Tece para si a história dos antepassados, daí citar o tataravô William Creek, o bisavô James Creek, o avô Wilfred Creek e o pai Roderick Creek, este último, observe-se que é o mesmo nome do personagem de $A$ Queda do Solar de Usher, Roderick Usher. Fernão, enquanto Lord Creek, precisava legitimar-se; legitimidade que não se faz necessária a Roderick, visto que consoante o narrador Solar e nome Usher estavam intimamente imbricados:

"e a conseqüente transmissão em linha reta, de pai a filho, do nome e do patrimônio, que afinal tanto identificaram ambos, a ponto de dissolver o título original do domínio na estranha e equívoca denominação de "Solar de Usher", denominação que parecia incluir, na mente dos camponeses que a usavam, tanto a família quanto a mansão familiar." (Poe, p. 245)

Essa busca de Fernão, essa imitação, essa procura de um laço nobre é uma característica do período romântico brasileiro, em virtude de pertencer ao período da Independência do Brasil e de fabricação de uma nacionalidade. Da mesma forma que Fernão persegue uma identidade, um passado aristocrático, assim é a Literatura Nacional com sua temática da Corte, com os valores da moral burgo-aristocrática, ou aristocracia da terra, a qual tinha por valores nobres aqueles que vinham de França ou da Inglaterra.

Ao compararmos o Lord de Gomes e o Lord Roderick, do filme de Corman, constatamos que esse, assim como o personagem de Poe não necessita de se auto-afirmar. O personagem de Corman mostra ao personagem Philip a galeria de retratos da família, e destrói o passado glorioso de cada antepassado, dizendo ter sido todos eles criminosos, vulgares, ladrões, e que a Casa é portadora de uma maldição, à qual Philip não acredita, mesmo tendo ouvido do próprio Roderick. Não há a preocupação nos personagens de Poe e de Corman de serem ou não aristocratas, ao contrário do personagem de Gomes. O personagem deste autor tomou para si o passado, a história de outrem, por não pertencer a uma história gloriosa sobre a qual pudesse se debruçar, história essa que era natural nos Rodericks.

Essa desvalorização de seu passado é fruto de um paradigma anglo e do reflexo de uma Iusofobia do período pós-colonial brasileiro; não condizente com a realidade ao analisarmos o significado dos nomes dos personagens utilizados por Gomes. Tal análise mostra-nos o equívoco de Fernão, e remete o nosso herói exatamente a essa tradição européia. $\mathrm{O}$ erro, 0 falseamento ocorria pela ausência de aceitação de um novo paradigma, face à histórica resistência do brasileiro em assumir a sua pátria, a sua descendência portuguesa. Outro enfoque também é o da inaceitação de Fernando em pertencer a uma raça exógena, saber-se fruto da ruptura do incesto. A endogenia lhe garantiria o sangue aristocrata. Fernão, Fernando, Fernanda, Matias não é uma mutação do mesmo no mesmo; antes, uma transmutação do mesmo em outros. Exemplo dessa ruptura endogênica, face as relações exôgenas, na história brasileira, vemos em Casa Grande e Senzala:

"... a nobreza nunca conseguiu formar uma aristocracia fechada; a generalização dos 
mesmos nomes a pessoas das mais diversas condições, como acontece com apelidos atuais, não é o fato novo da nossa sociedade; explica-o assaz a troca constante de indivíduos, duns que se ilustram, doutros que voltam à massa popular donde haviam saído;..."(Freyre, p. 245)

A sociedade brasileira, sempre foi móvel e flutuante, principalmente nos primeiros séculos, não se isolando, tampouco se estratificando dentro de fronteiras intransponíveis. Tão móvel quanto nosso Fernão, tão móvel quanto a sua origem, quanto os deuses que cá o deixaram.

Fernando/Fernão significa inteligente, protetor, ousado, corajoso, nome muito comum nas casas reais de Castela e Aragão. Resgatemos aqui a história do Condato de Portucale e do Condato de Castela.

Em 1094, Afonso VI, Rei de Leão, um dos reinos em que a Península lbérica era dividida (os outros: Castela, Aragão e Navarra), casa suas filhas, Urraca com o Conde Raimundo de Borgonha, e Teresa com D. Henrique. Ao primeiro genro, doa uma extensa região de terra correspondente à Galiza; ao segundo, o território compreendido entre o rio Minho e o Tejo, com o nome de "Condato de Portucalense." ( Moisés, p. 21)

O nome de Fernão está intimamente ligado à história portuguesa - a Aragão a Castela -, assim como o nome Matias, deriva do hebraico Matatías, que significa Dom de Jeová ou de Deus, está ligado ao povo de Israel. Estão presentes na formação de Fernão o luso, o judeu e o mouro. Assim como o povo Judeu fora escolhido por Deus, o Lusitano viu-se como o povo mensageiro. Como esses povos, Fernão Matias também possuía laços com o divino. Se formos mais além, podemos compará-lo, não só a esses povos, mas a um Enéias, fundador de Roma, ou à própria Europa, fruto direto da paixão de Zeus. Ao contrário de Macunaíma, não se transformou em constelação, participando da ordem cósmico dos deuses, porque já pertencia a eles. O retornar à pátria (o acordar diante da nau que voltava para pegá-lo) é essa integração a esse cosmo tão perseguido, tão almejado durante séculos. Por fim, Ribeiro, que significa pequeno rio, que flui para outros rios - nascente, formando tantos outros rios, assim como as possibilidades narradas por Gomes de nosso personagem. Matias tem nome e sobrenome Fernão Matias Ribeiro, mas recusa a sua tradição, a sua identidade.

Aproveitando-nos de ter entrado nos nomes, busquemos uma possível razão para Gomes não ter adotado o nome de Madeline. Corman preserva o nome original da personagem de Poe, mas Gomes utiliza-se de Eleonora. Este nome tem como variante Lenora, nome utilizado em $\mathrm{O}$ Corvo, obra de Poe, poesia que segundo Oscar Mendes, irradia de seus versos uma intensidade muito grande de pesadelo. (Poe, p. 893) Esse pesadelo que será Madeline para os Rodericks, tanto do filme quanto do conto; essa Eleonora que será um pesadelo para Lord Creek e que soará para todos eles como um ritornelo: "Nunca, nunca, nunca mais..."Somando-se a isso, temos o significado de Lenora: meu Deus é luz; Helena, a que fora roubada, e a destruidora de homens, podendo significar o Teluka que fora roubado, o Fernão destruído em sua virilidade inicial, transformando-se em um "sol de crepúsculo, cuja luminosidade difusa, que perturba, que enlouquece, prometia os encantos do interdito, daquilo tudo que as chãs consciências renegavam e tinham medo." (Gomes, p. 216)

Continuando a pensar a personagem Madeline/Eleonora, no filme, no conto, e no romance de Gomes, é lugar comum entre os dois primeiros, a participação no enterro da irmã de Usher, tanto do amigo de Roderick, quanto de Philip, namorado de Madeline, na versão de Poe e de 
Corman, respectivamente. Somando-se a esse dado, Madeline, em ambas as versões, quanto Eleonora são vítimas da catalepsia, no entanto, a morte da primeira foi sempre aparente nas duas versões. Acometida por um ataque de catalepsia, fora propositadamente enterrada pelo irmão, com a participação daqueles, os quais não sabiam da doença da irmã de Roderick. Por sua vez, Em Noite na Taverna, nem Abreu, nem Varela, nem o narrador participam do enterro, tampouco conheceram Eleonora viva. Ela é um mero ritornelo. Dor da qual eles participam por idealização romântica, não por interação, por convivência. Choravam quem desconheciam, por um ideal, assim como eram o pranto dos poetas.

Em se tratando da revelação da falsa morte de Madeline, no conto, o amigo de Roderick fica a par por intermédio do próprio Usher, por uma questão de crise de consciência do fatricida; no filme, o mordomo, tentando defender o patrão da acusação de Philip de que o enterro da irmã de Roderick fora precipitado, mencionou sobre a doença que sofria Madeline. Em Gomes, a revelação de quem era Eleonora deu-se por vingança do cocheiro. A fala foi proposital, fruto da luta de classes, de pessoas que se digladiavam, por rancor e por interesses particulares. Neste último caso ocorreu a interferência do forano dentro. A classe humilhada denunciou as falcatruas do dominador, e conseqüemente a alienação da classe intermediária, intelectualizada, prepotente, incapaz de ouvir aquela e dar-lhe crédito. Esse descrédito era oriundo da idealização que a classe intelectual tinha da aristocracia. Esta era vista como honrada, capaz de amar, cavalheira; qualidades estas que os romances românticos não reconhecem na camada popular. Notemos que diante da proposta do cocheiro de revelar a verdade sobre o Lord ao jovens, Abreu responde: "- Não ouses sujar de lama o nome desse homem!", nesse caso, o nome do Lord.

A partir desse ponto, mergulhamos no capítulo III As Revelações do Cocheiro. Esse capítulo nos remeterá ao romance As Minas do Rei Salomão, de H. Rider Haggard, do qual provavelmente Gomes retirou o nome para seu romance "Os Rios Inumeráveis". Por Três vezes surge o termo inumeráveis. Na página 29 lemos "Nas ravinas, cavadas pelas enxurradas de séculos, faiscam riachos inumeráveis", além desse uso, destaquemos também a utilização da expressão "as colunas inumeráveis" (Haggard, p. 190). Mas a influência do romance de Haggard não se limita apenas ao título. É nele que Gomes se pauta para criar a verdadeira história da vida de Fernão Ribeiro.

No capítulo III, o cocheiro, esse sufixo eiro - denotador de classe, de profissão, de nacionalidade na Língua Portuguesa - será o emissor do discurso da Verdade. É esse homem comum, lesado em seus direitos, aprisionado pela classe dominante que tirará o véu, destronará a falsa nobreza. Somente quem nada mais tem a perder é capaz de pronunciar um discurso verdadeiro - retornamos aos ensinamentos do velho mestre Machado de Assis recordando Memórias Póstumas de Brás Cubas, nas confissões de um defunto autor descompromissado com a vida.

A história narrada pelo cocheiro é uma paródia da aventura de Haggard em As Minas do Rio Salomão. Se estávamos diante da ficcionalidade de Fernão, agora estamos diante da ficcionalidade do cocheiro Menezes. São textos contra textos. Menezes conta sobre as aventuras do Lord, como o conheceu e como este roubara Teluka. A paródia é evidente no romance de Gomes, exemplo temos na aventura por que passaram Fernão, Menezes e seus amigos em busca de riquezas, as quais se encontravam "num reino encravado na África, onde riquezas e mais riquezas aguardavam o aventureiro que tivesse a ousadia de as ir apanhar." (Gomes, p. 233). Fernão fica a par dessas riquezas através de Alain Quatermain (ou Alão Quartelmar na tradução de Eça de Queirós), narrador e aventureiro da obra de Haggard. 
Quartelmar recebera das mãos de José Silveira o mapa das Minas de Salomão, e partira numa expedição acompanhado do Barão Incubu, de capitão John, ou Boguan, grandes homens e amigos, somando-se a eles Infandós, o rei dos Kakuanas, não sem antes descrever para todos a terra de destino:

"E contou-me então que no interior, muito no interior, descobrira ele uma cidade antiquíssima, toda em ruínas, que tinha a certeza de ser Ofir, a famosa Ofir da Bíblia. Lembro-me a impressão e o assombro com que eu escutei a história dessa cidade fenícia perdida no sertão da África, com os seus restos de palácios, de piscinas, templos, de colunas, derrocadas!.." (Haggard, p. 17)

Cada um dos personagens de Haggard, no percurso da aventura, respeitava o outro, dentro de um pacto de honra cavalheiresco, o que não houve da parte de Fernão. Este seduziu o capitão da nau, apropriou-se posteriormente do comando, incitou Teluka contra Meluka seu irmão; roubou a tribo, e raptou o jovem, fugindo para Stouthampton, Inglaterra, local para onde segue o Barão Incubu, Henrique Curtius.

As semelhanças aí não terminam. Lembremos que Gagula, a velha feiticeira da tribo que apoiava Tuala, rei que se apropriara do trono do pai de Infandós, possui mais de trezentos anos. Sua memória já se perdeu no tempo a ponto de Gagula não saber se foi ela ou um antepassado seu que participou de determinados fatos. Assim é Fernão, para o leitor de Os Rios Inumeráveis, não pode dizer tratar-se da mesma pessoa. O tempo transmudou-o, passou os seus limites, assim como Gagula: "Era uma mulher evidentemente, uma mulher velhíssima, tendo passado todos os limites conhecido da vida humana. ( Haggard, p. 119), e na seqüência a própria velha diz: "-Sou velha! Velha! Velha! Tenho visto correr muito sangue. ...Os vossos pais já me conheceram; e os pais dos vossos pais; e os outros pais que geraram a esses. Tenho visto muitas coisas, aprendi muitas coisas". (Haggard, p. 121) Mais adiante Gagula se confunde com outras, não sabe se foi ela mesma a condutora dos homens que vieram no passado ou se ela mesma: "Outrora veio um homem, encheu um saco dessas pedras brilhantes, e uma grande desgraça caiu sobre ele! E foi uma mulher que o levou, e que se chamava Gagula. Talvez fosse eu! Talvez fosse minha mãe! Ou a mãe de minha mãe! Quem sabe? (Haggard, p. 182), similar ao retrato de nosso Fernão, Fernando, Boto, Matias, Lord Creek e outros. É o mesmo, ou quem sabe não seja seu pai, ou o pai de seu pai. Como Gagula, ele já vivera muito!...

Quarto Capítulo. Hora em que o homem e seu discurso serão postos em xeque. As palavras terão de estar condizentes com as coisas. Esse é o princípio de verdade greco-aristotélica. Tanto no filme, quando no conto de Poe, se a coisa não era o que se havia dito dela, rebelavase, erguia-se da tumba e investia contra o falante. Madeline ressurgiu enlouquecida e caiu sobre o irmão Roderick.

"Durante um instante permaneceu ela, tremendo e vacilando, para lá e para cá, no limiar. Depois, com um grito profundo e lamentoso, caiu pesadamente para frente, sobre seu irmão, e, em seus estertores agônicos, violentos e agora finais, arrastou-o consigo para o chão, um cadáver, uma vítima dos terrores que ele mesmo antecipara". (Poe, 257)

O texto menciona "arrastou-o consigo", não houve uma luta como ocorre na versão de Corman. No filme há uma luta final através da qual Madeline leva consigo aquele que impediu a ruptura do incesto, isto é, sua saída da Casa e o seu casamento com Philip Winter. Na luta cai o lampião incendiando a mansão. $O$ jovem foge. De fora dos muros vê um raio atingir o casarão, a 
fenda abrir-se, o lago receber o solar e o nome dos Usher. A cena do filme não difere do conto: "... houve um longo e tumultuoso estrondar, semelhante à voz de mil torrentes... e o pântano profundo e lamacento, a meus pés, fechou-se, lúgubre e silentemente, sobre os destroços do "Solar de Usher". (Poe, p. 257)

Não foge muito Gomes desse final. A imagem da Lua, o estrondo:"...houve um longo, tumultuoso estrondo, como mil vozes de cataratas: era a mole que desmoronava, sob o peso de tanta infâmia. E o charco, então, piedosamente, abriu as fauces para receber o que restara da Casa de Creek."( Gomes, p., 244). Apesar das imagens serem as mesmas, o conteúdo é outro. Em primeiro lugar a realidade não confere poder ao discurso, antes sim o desmascara. E a partir do momento em que a máscara é tirada, os jovens, decepcionados, começam a ver o que não queriam ter visto;

"Aberta a porta, Menezes puxou um dos cortinados e não pudemos reprimir um grito de horror: o solar, que nas trevas, nos ludibriara com a ilusão duma decandência faustosa, era um pardieiro: o soalho estava todo carunchado, e a poeira e as teias de aranha acumulavam-se sobre os móveis desmantelados, sobre os rotos cortinados. Não batasse isso, a rachadura da parede aumentara consideravelmente, e a luz do crepúsculo invadia o solar, revelando-lhe toda a hediondez. Que desolação!" (Gomes, 241)

Eis a lupa machadiana que thes foi dada. A realidade se impôs ao sonho, visto que ela é mais forte de que qualquer discurso. O eiro à custa de sua vida desmascarou o quanto ultrajante era aquela aristocracia, para esclarecer a classe que vivia no sonho a que esta almejava: "Sujar de lama? Oh! Que pilhéria, meu jovem! Impossível sujar de lama a quem sempre esteve atascado nela!"(Gomes, p. 228)

Contudo, ao contrário de Roderick que morre, visto que o processo endogênico havia dizimado a família; Lord Creek era exógeno, eis por que o narrador menciona que "por um instante, tive a sensação de ver um vulto saltando uma das janelas, as vestes em chamas, rolar pelo chão e desaparecer nas capoeiras que circundavam a mansão. Seria Menezes? Seria o Lord? Ou seria apenas ilusão criada por minha mente enfebrecida? (Gomes p. 244)

O final da obra nos comprova que, certamente não era ilusão, tampouco, um vulto fabricado por uma mente enfebrecida. Os deuses retornaram para ver o mundo que Fernão configurara. "Então, como haviam prometido, vinham eles de volta a ver se tínhamos cumprido nossa missão". (Gomes, p. 422)

\section{BIBLIOGRAFIA}

AZEVEDO, Álvares. Noite na Taverna. Rio de Janeiro : Editora Três, 1973.

COSTA, Emília Viotti da. Da Monarquia à República : momentos decisivos. São Paulo : Editora Brasiliense. 1987

CORMAN, Roger. A Queda do Solar de Usher. Filme. 
FOUCAULT, Michel. A Ordem do Discurso, Trad. Laura Fraga de Almeida Sampaio, São Paulo : Edições Loyola, 3ª edição, 1996.

FREYRE, Gilberto. Casa Grande \& Senzala. Rio de janeiro : Editora Nova Aguilar, 1977

GOMES, Álvaro Cardoso. Os Rios Inumeráveis. Rio de Janeiro: Topbooks, 1977

HAGGARD, H. Rider. As Minas de Salomão. Trad. Eça de Queirós. Rio de Janeiro : Editora Nova Fronteira, 1992.

HUYSMANS, J.K. Às Avessas. Trad. de José Paulo Paes. São Paulo : Companhia das Letras, 1987.

MOISÉS, Massaud. A Literatura Portuguesa. São Paulo : Cultrix, 1982.

OSCAR, Wilde. Obra Completa : vida e obra. Tradução: Oscar Mendes. Rio de Janeiro : Editora Nova Aguilar, 1980.

POE, Edgard Allan. A Queda do Solar de Usher. Rio de Janeiro : Editora Nova Aguilar,1981.

ROUANET, Sérgio Paulo. O Olhar lluminista In: O Olhar/ Adauto Novaes ... [at. al.] São Paulo : Companhia das letras, 1988. pp. 125-148 